\title{
AN INVESTIGATION OF FUEL EFFICIENCY IN HIGH SPEED VESSELS BY USING INTERCEPTORS
}

\author{
A. Gültekin AVCI ${ }^{1}$, Barış BARLAS², Aykut Ibrahim ÖLÇER ${ }^{3}$
}

1 Istanbul Technical University, Faculty of Naval Architecture and Ocean Engineering, Phone:+902122856464, email: g.avci@itu.edu.tr 2 Istanbul Technical University, Faculty of Naval Architecture and Ocean Engineering, Phone:+902122856464, email: barlas@itu.edu.tr

3 World Maritime University ,Maritime Energy Management Specialization, Phone: +46-40-356377, email: aio@wmu.se 


\section{Contents}

- Introduction

- Trim Interceptors

- Interceptors vs. Traditional Trim Tabs

- Application of Trim Interceptors

- Experimental Study

- Preliminary Results

- Conclusion 


\section{Introduction}

- Marine vehicles advancing steadily at especially at High Froude numbers experience sinkage and trim motions because of the hydrodynamic forces acting on the hull.

- After a while from beginning to move, a well-designed high speed boat passes to the planning regime

- It is also of practical importance to include sinkage and trim effects in calculation of the wetted surface and so calculation of the ship resistance for high speed marine vessels.

- To deal with these unexpected motions, nowadays, generally trim interceptors are used for ride and trim control, and also for steering

- A sub-work of a PhD study entitled as "Numerical and Experimental Investigation of Trim Interceptors on Stepped and Unstepped High Speed Hulls." which a number of parameters to deploy interceptors with different positions, depth and also effect with stepped and un-stepped hulls, to create an innovative literature reference. 


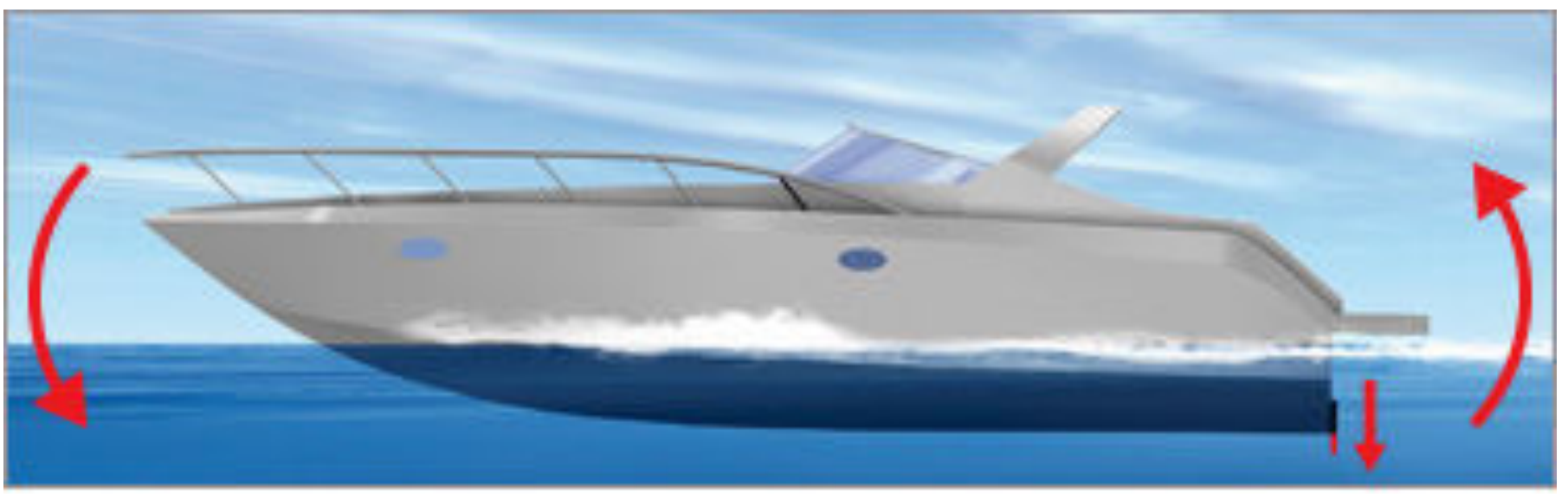

\section{Trim Interceptors}
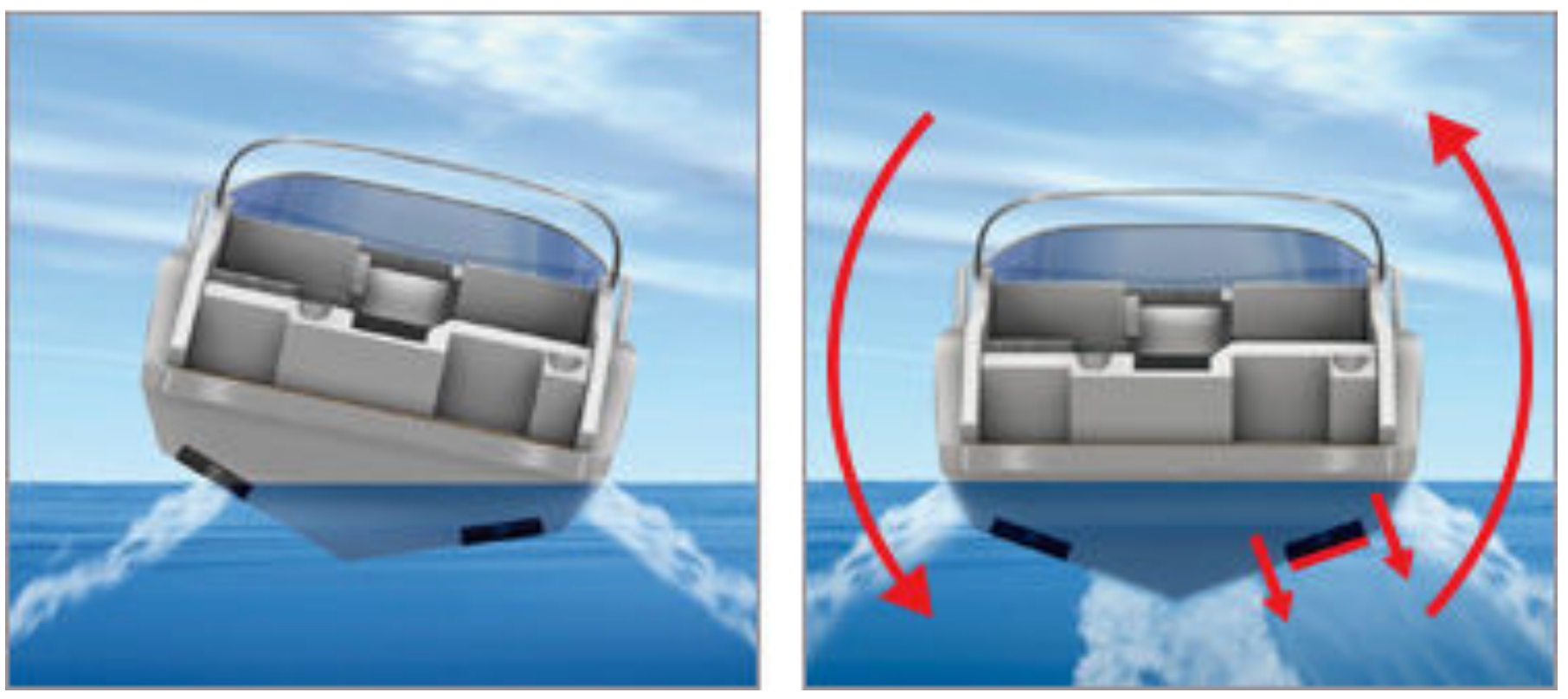


\section{Trim Tabs}

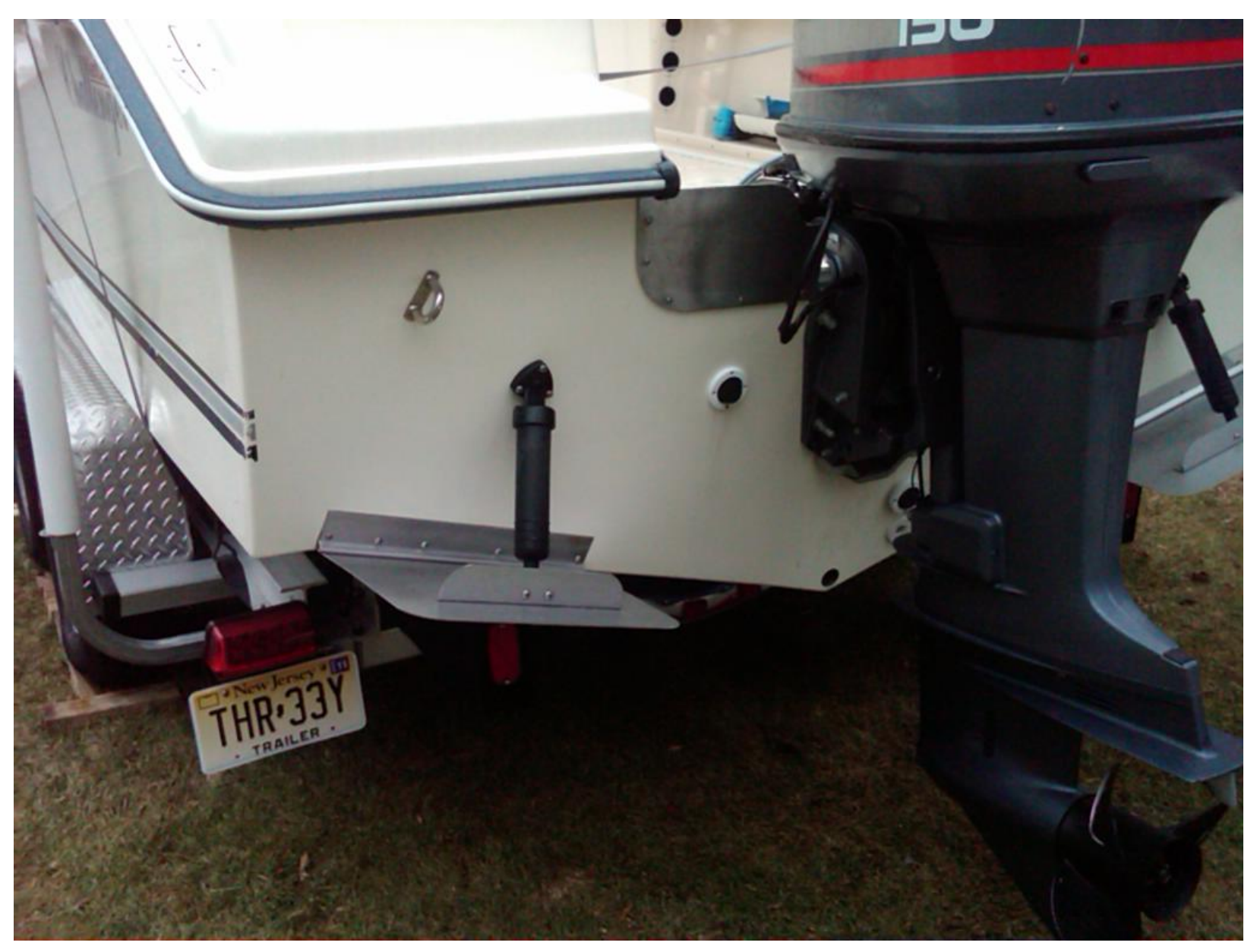



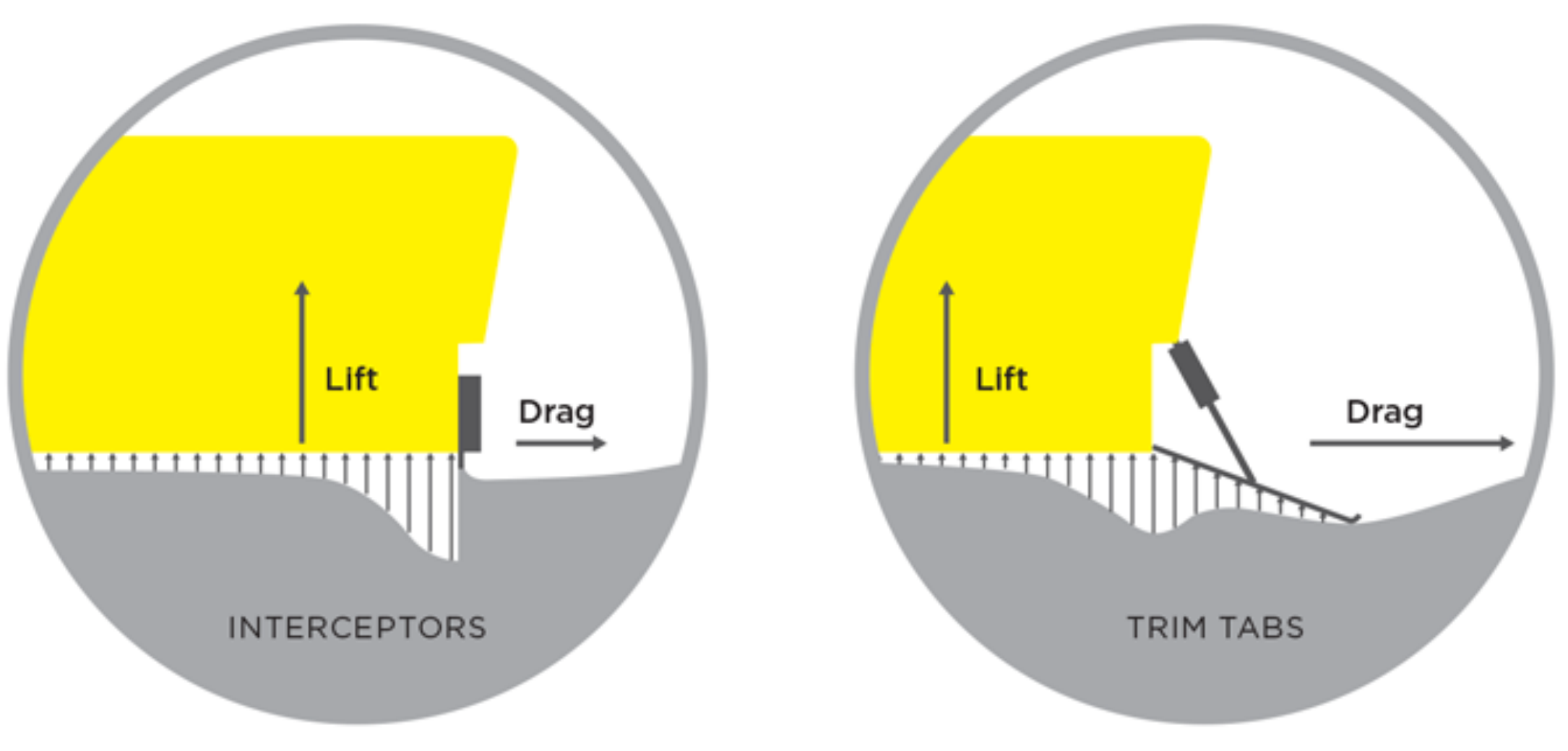


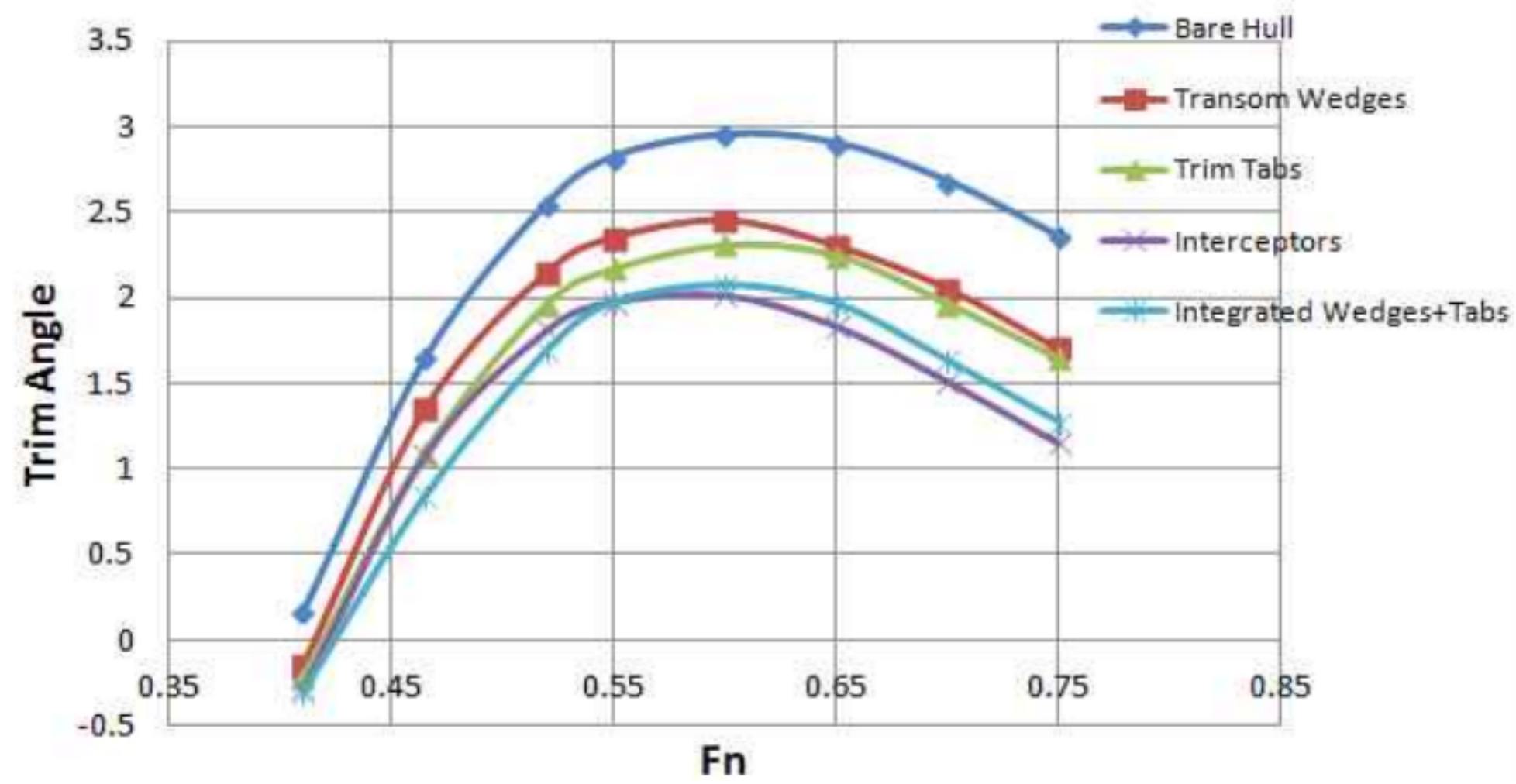

Experimental investigation of dynamic trim control devices in fast speed vessel Kwang-Cheol Seo.Nithin Gopakumar*.Mehmet Atlar**

School of Marine Science and Technology, Newcastle University, Newcastle, NE1 7RU, United Kingdom 


\section{Application of Trim Interceptors}

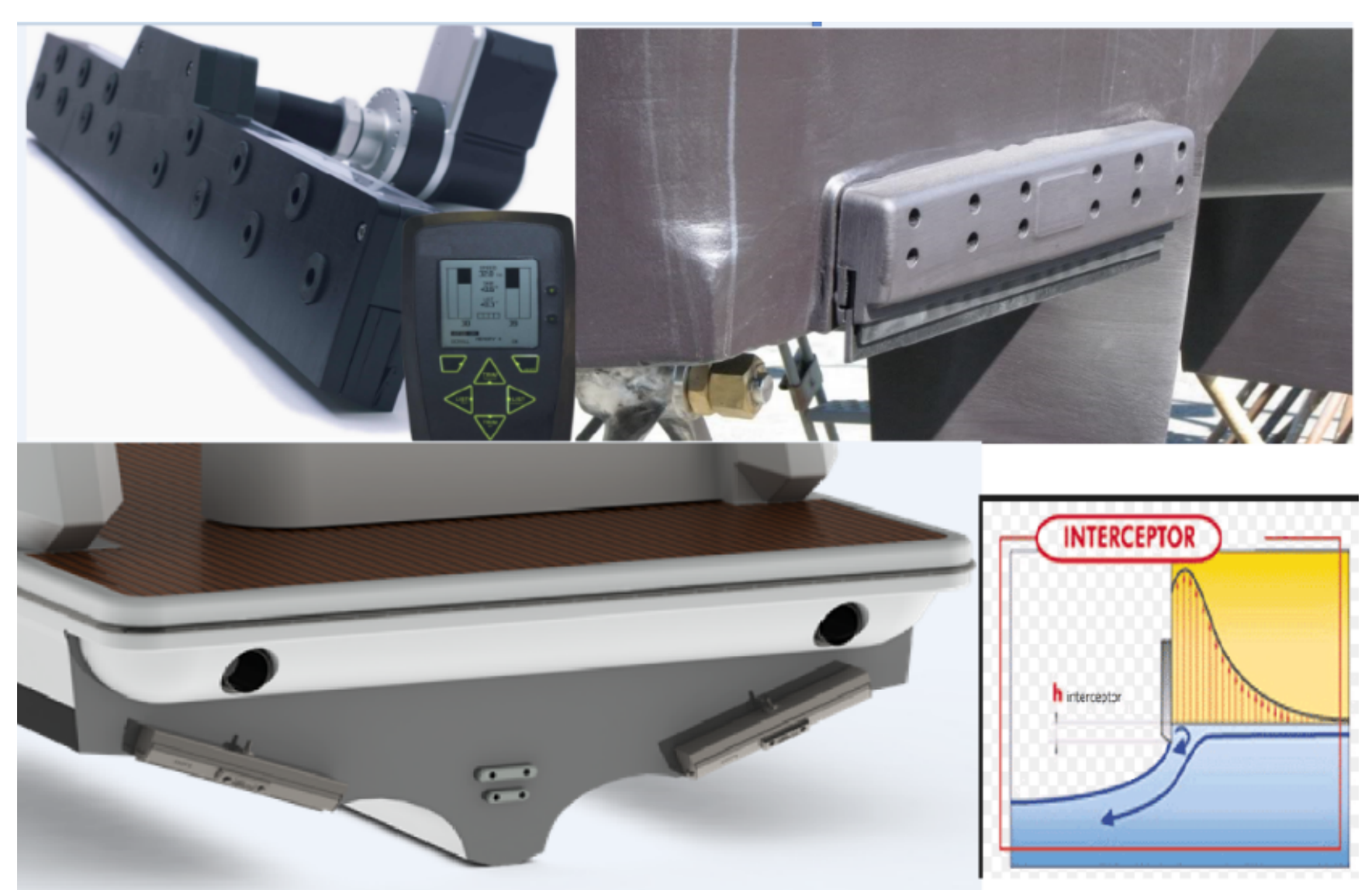




\section{Application of Trim Interceptors}

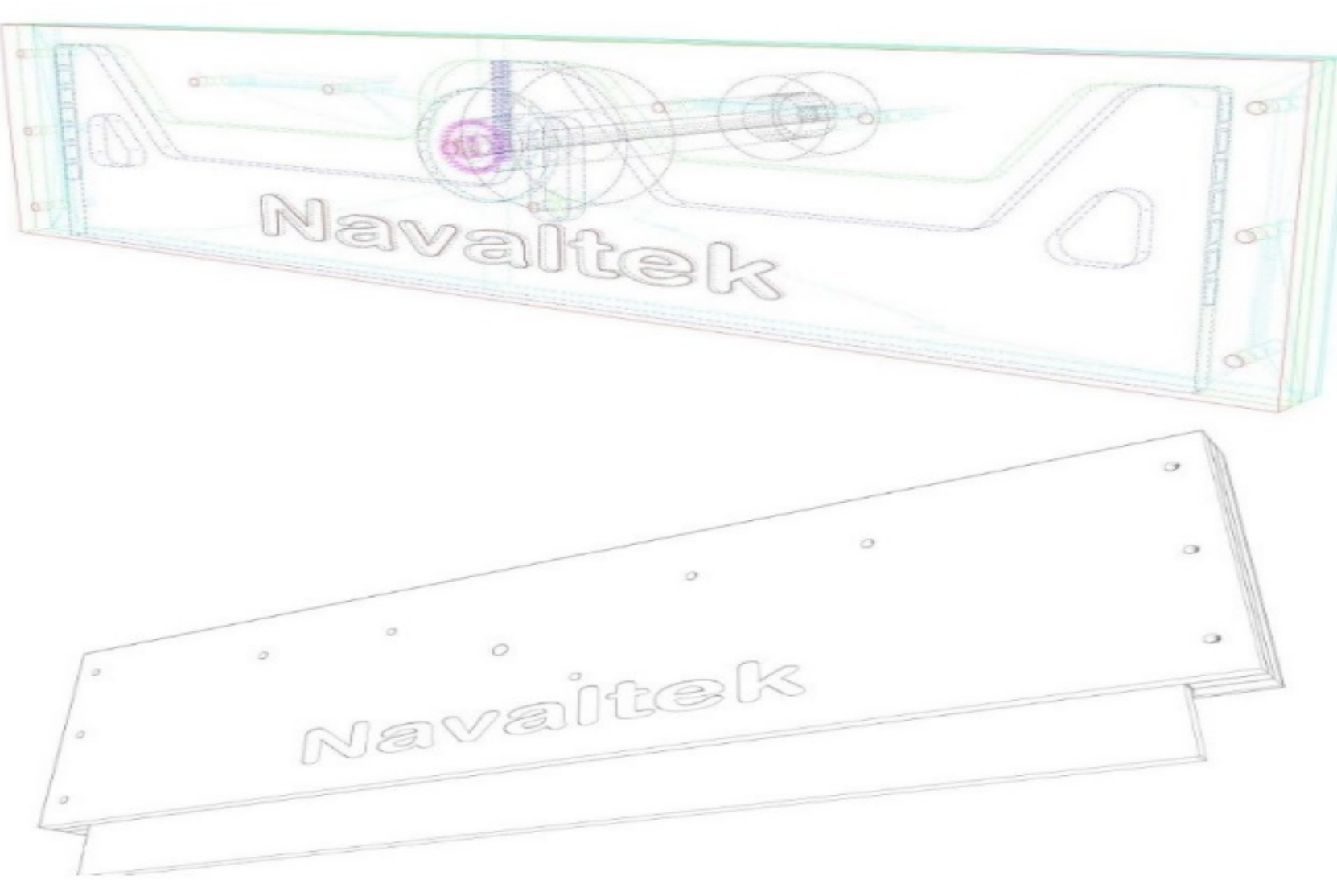




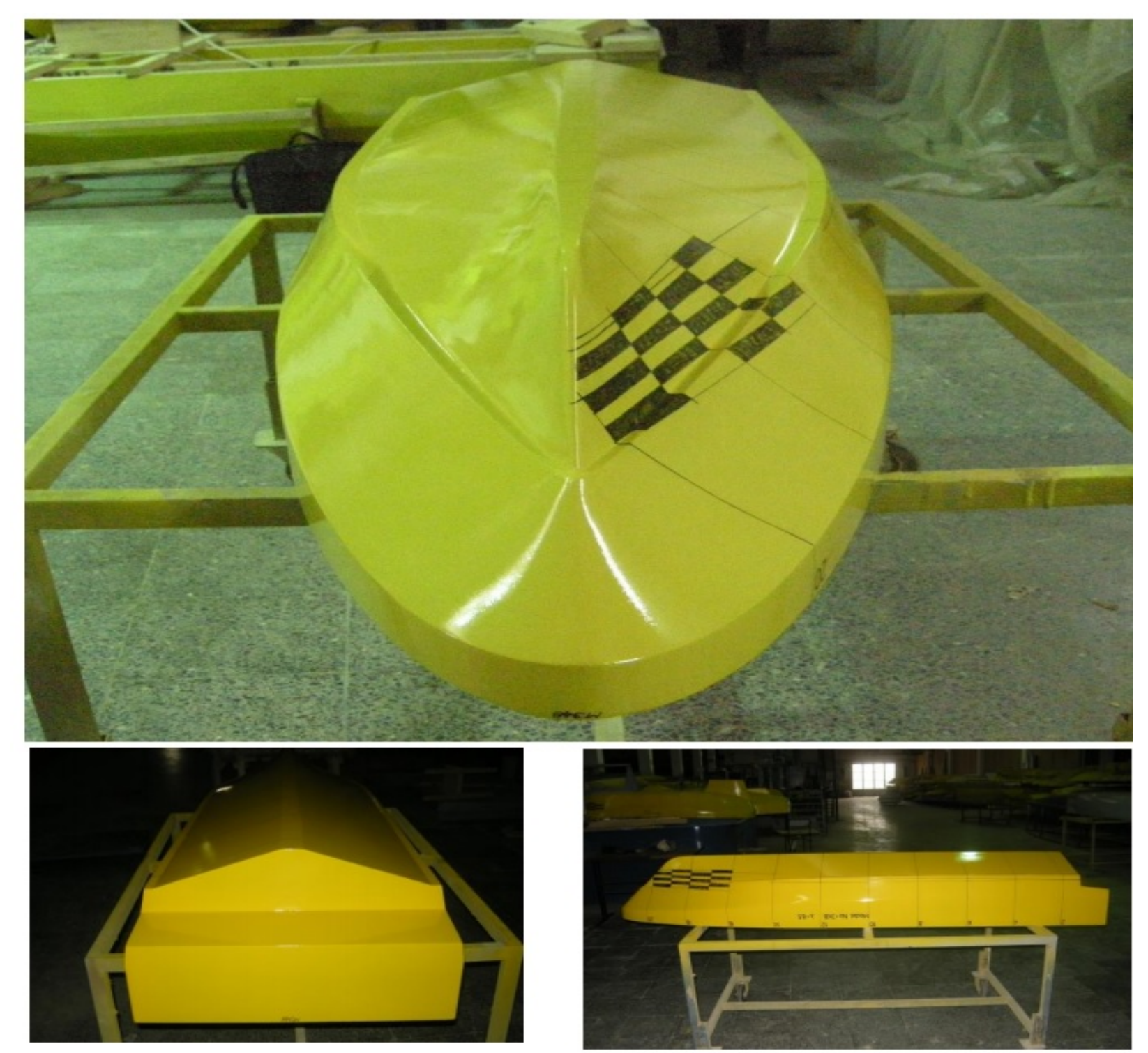

\section{Experimental Study}

(Where: Ata Nutku Ship Model Testing Laboratory, Istanbul Technical University, Istanbul, Turkey)

\begin{tabular}{|c|c|c|}
\hline & & Scale (8.5) \\
\hline Test condition & & Model \\
\hline Length between perpendiculars & $\mathrm{L}_{\mathrm{BP}} \quad(\mathrm{m})$ & 2.031 \\
\hline Length on waterline & $L_{W L} \quad(m)$ & 1.934 \\
\hline Wetted length & $L_{w s} \quad(m)$ & 1.934 \\
\hline Breadth & B $\quad(m)$ & 0.588 \\
\hline Draught (amidships) & (m) & 0.108 \\
\hline Draught (AP) & $T_{A} \quad(m)$ & 0.108 \\
\hline Draught (FP) & $T_{F} \quad(m)$ & 0.108 \\
\hline Displacement volume & $\nabla \quad\left(m^{3}\right)$ & 0.053 \\
\hline Displacement & (ton) & 0.053 \\
\hline Nominal wetted surface area & $s_{0} \quad\left(m^{2}\right)$ & 0.989 \\
\hline Transom area & $A_{T} \quad\left(m^{2}\right)$ & 0.0256 \\
\hline Centre of transom area & $H_{T} \quad(m)$ & 0.0741 \\
\hline Block coefficient & $c_{B}$ & 0.436 \\
\hline Prismatic coefficient & $c_{p}$ & 0.715 \\
\hline Midship area coefficient & $c_{m}$ & 0.611 \\
\hline Waterplane area coefficient & $c_{\text {wp }}$ & 0.755 \\
\hline Longitudinal centre of buoyancy & $\operatorname{LCB}(m)(+f w d)$ & -0.128 \\
\hline Longitudinal centre of floatation & $\operatorname{LCF}(m)(+f w d)$ & -0.130 \\
\hline Service speed & $v_{s}$ & $4.411 \mathrm{~m} / \mathrm{s}$ \\
\hline
\end{tabular}




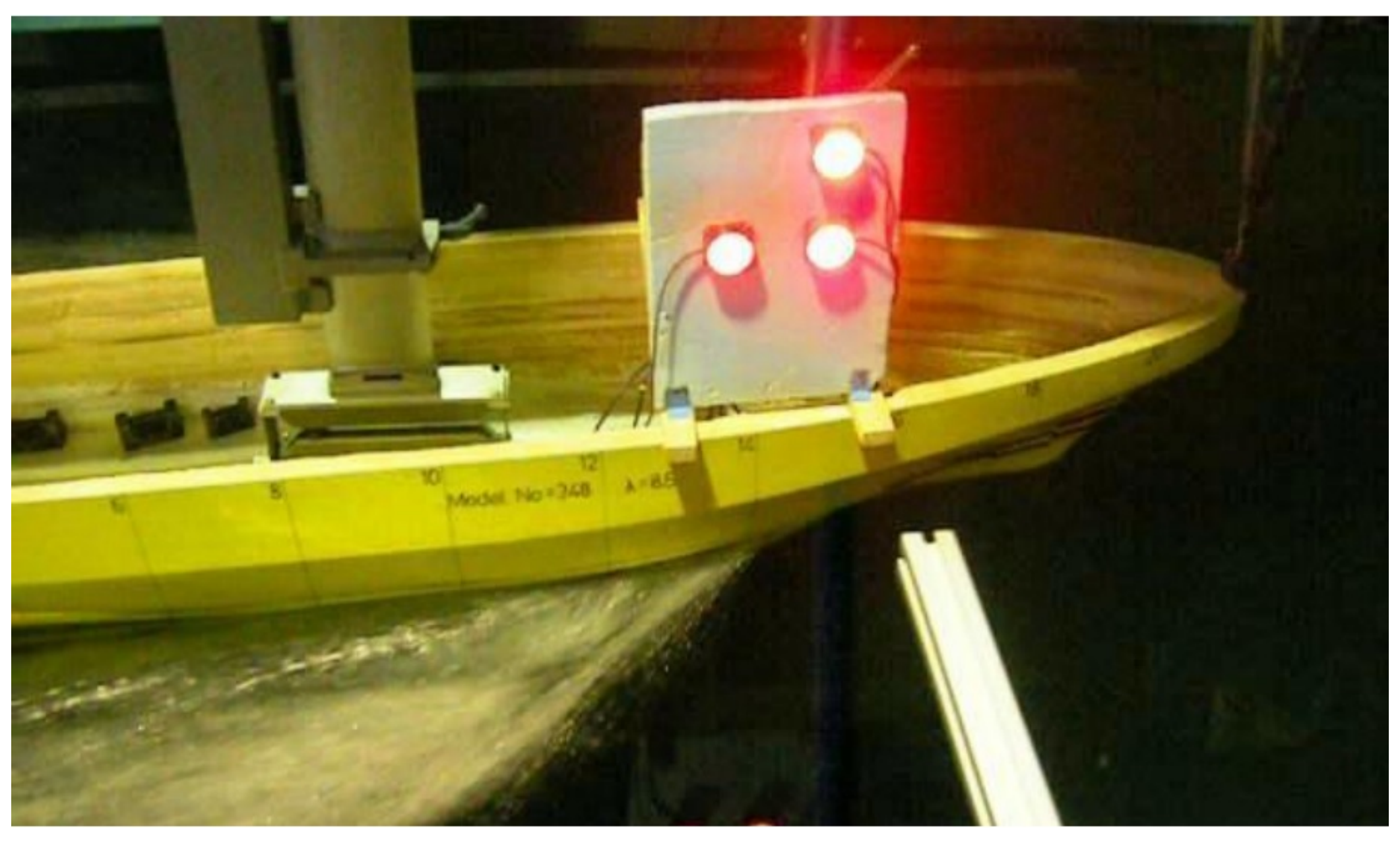

Trim measurements using high speed camera system (HSCS) 


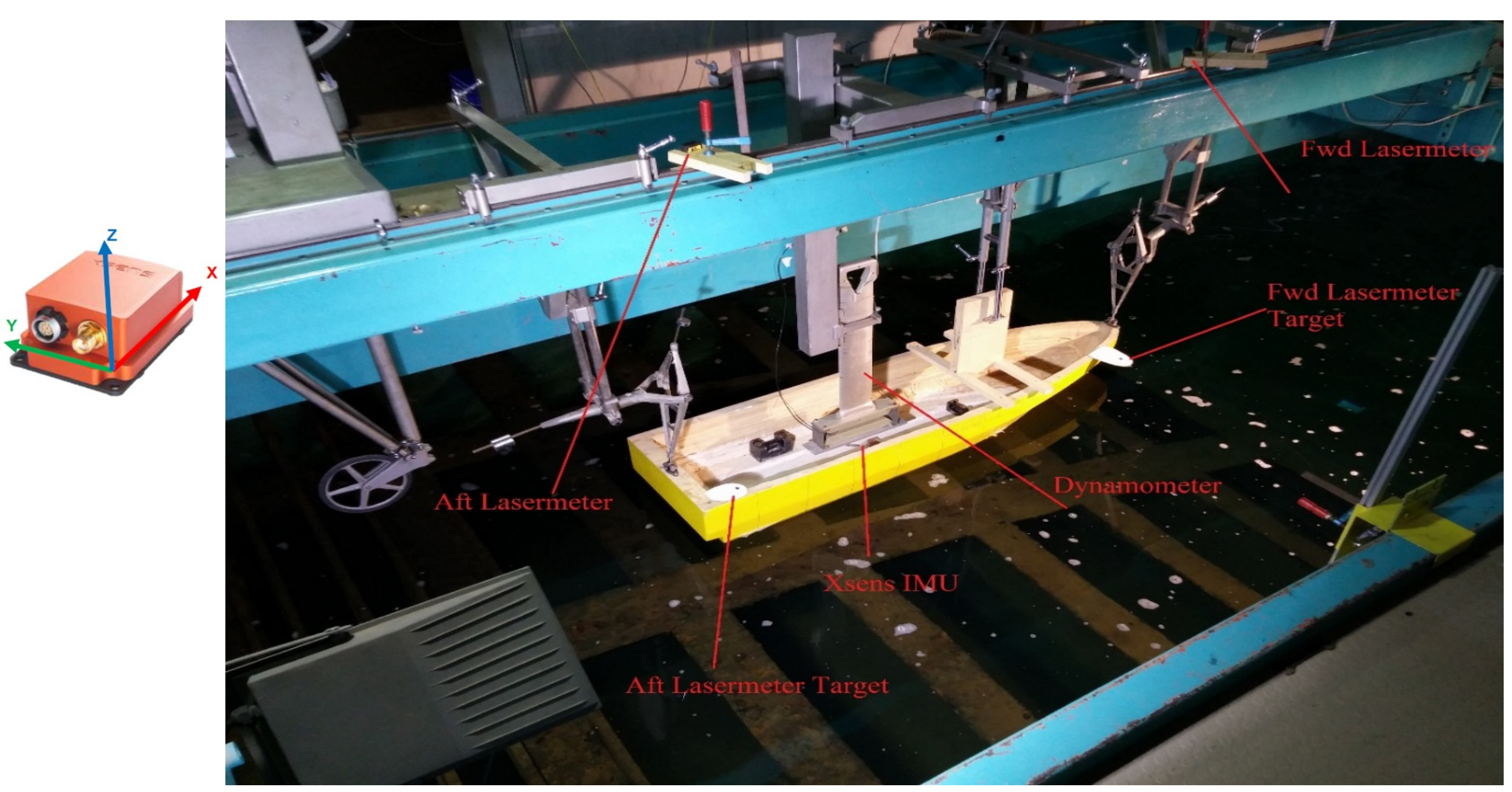



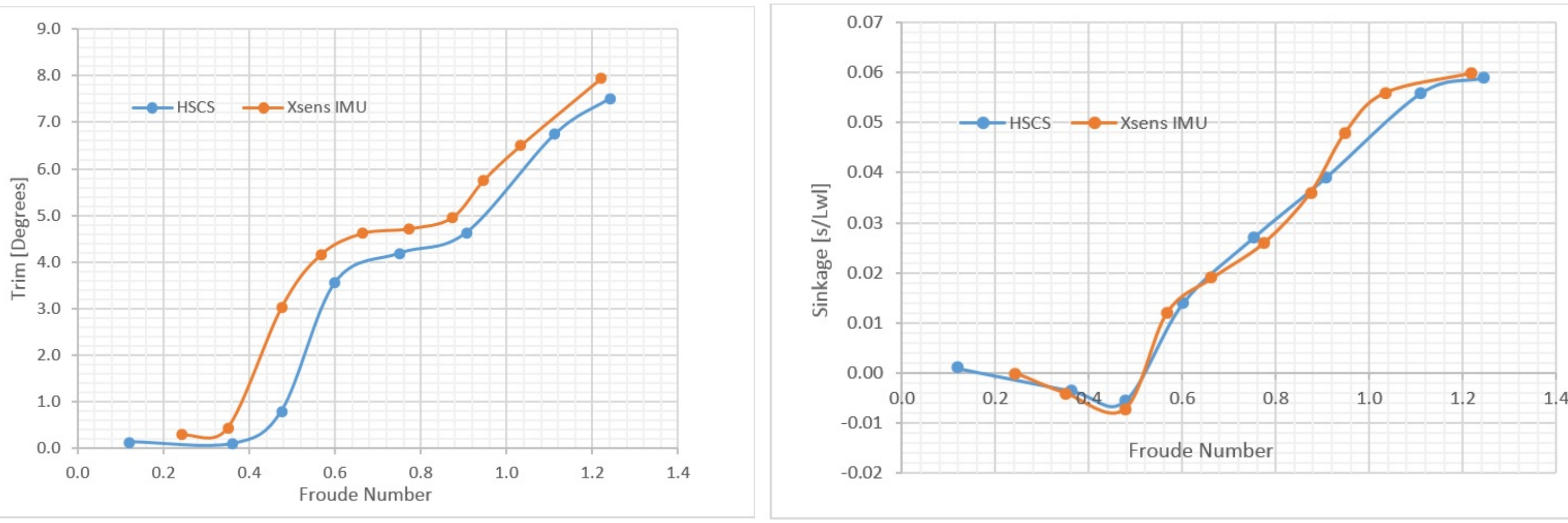


\section{THE EXPERIMENT MATRIX}

\begin{tabular}{|c|c|c|c|}
\hline Interceptor position & Chine & Middle & Bottom \\
\hline Interceptor height & & & + \\
\hline $1 \mathrm{~mm}$ & + & + & + \\
\hline $2 \mathrm{~mm}$ & + & + & + \\
\hline $4 \mathrm{~mm}$ & + & + & + \\
\hline $6 \mathrm{~mm}$ & + & + & + \\
\hline $8 \mathrm{~mm}$ & + & + & + \\
\hline $10 \mathrm{~mm}$ & + & + & + \\
\hline
\end{tabular}

203 experiments carried out

(52 experiments for close to chine placed interceptor + 59 experiments for middle placed interceptor + 63 experiment for near keel placed interceptors + 29 experiments for bare hull) 


\section{Interceptors Mounted Near The Chine of The Transom Edge $\quad$ interceptors Mounted in The Mid of The Transom Edge $M$}

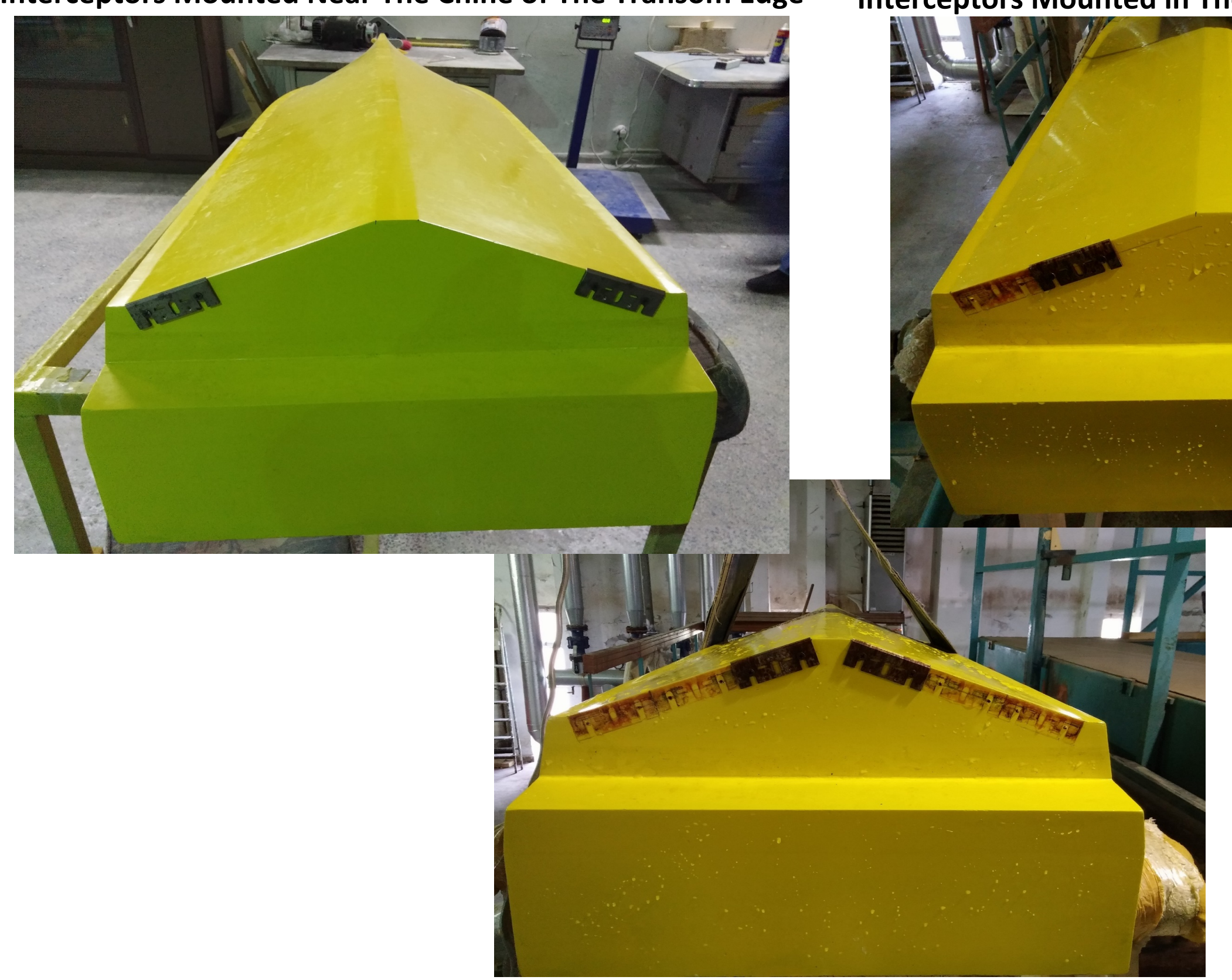

Interceptors Mounted Near The Keel of The Transom Edge 


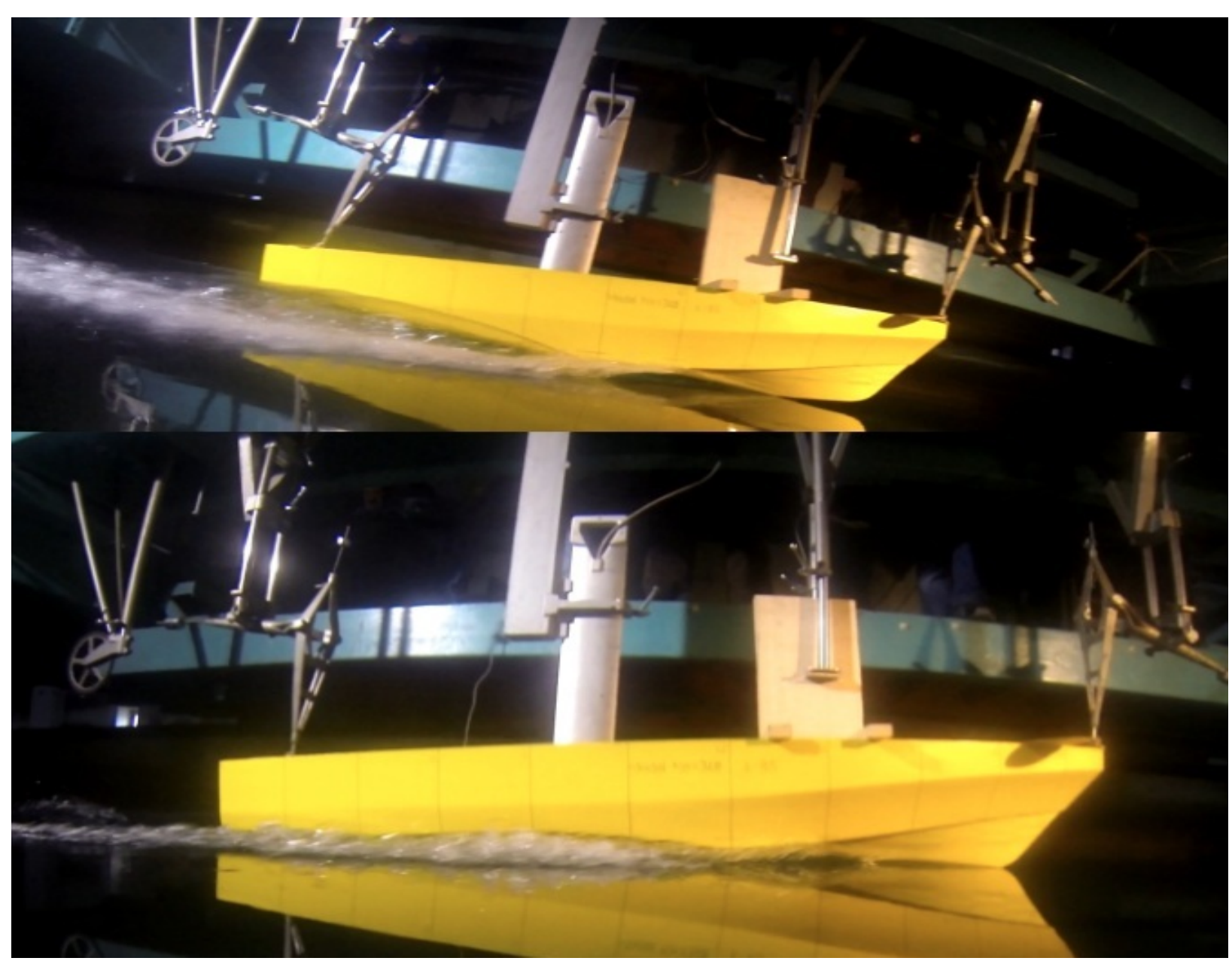




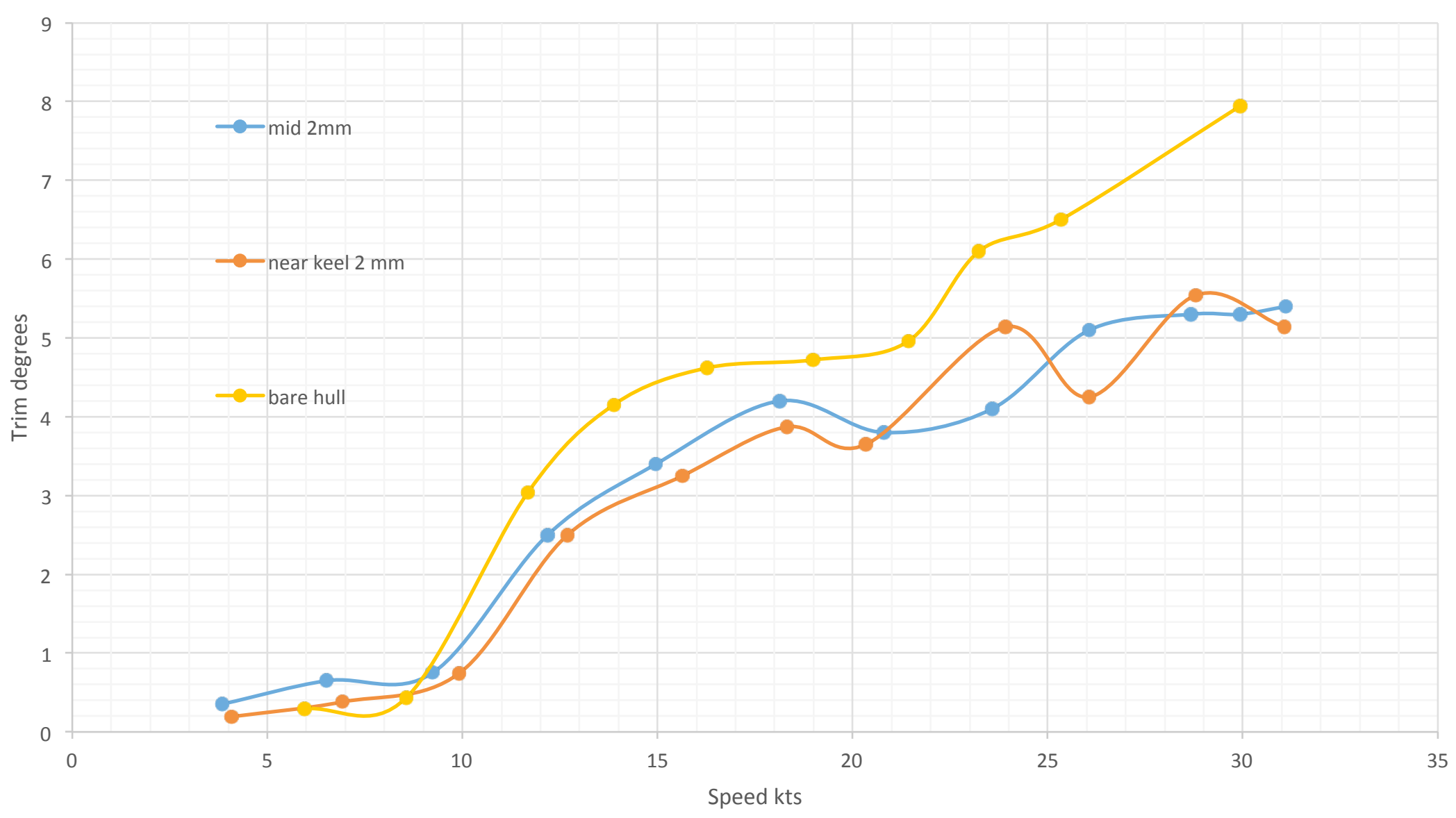




\section{MARENER}

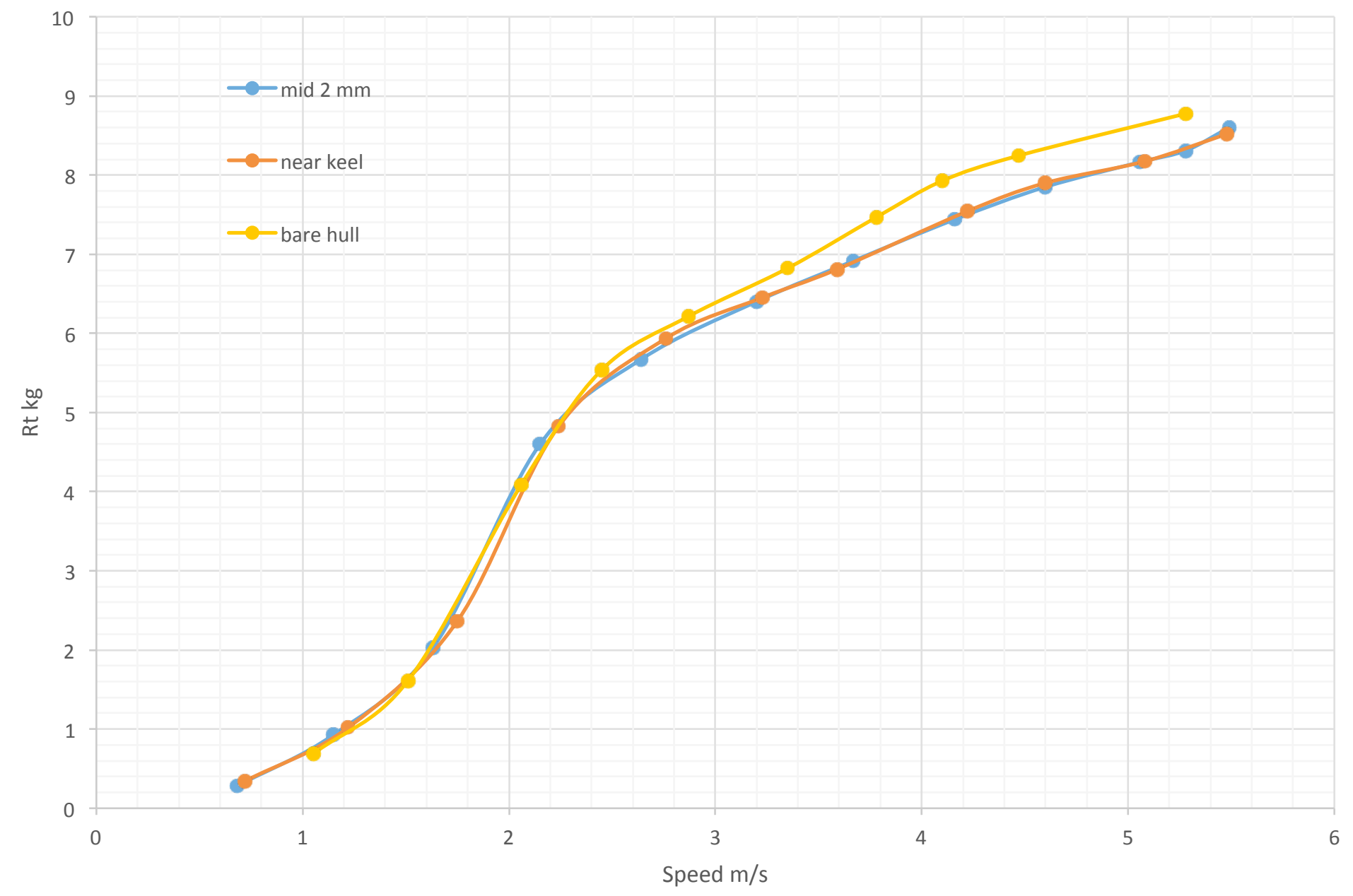




$$
\begin{gathered}
C \downarrow T=a \downarrow 0+a \downarrow 1 F n+a \downarrow 2 A+a \downarrow 3 T \\
E=\sum 0 \uparrow n=[C \downarrow T-a \downarrow 0-a \downarrow 1 F n-a \downarrow 2 A-a \downarrow 3 T] \uparrow 2
\end{gathered}
$$

$$
\partial E / \partial a \downarrow i=0
$$

$$
\begin{aligned}
& C \downarrow T \downarrow \text { Bottom }=21.512-11.787 F n-1.053 A-0.314 T \\
& C \downarrow T \downarrow \text { Middle }=20.103-11.910 F n-0.113 A-0.028 T \\
& C \downarrow T \downarrow \text { Chine }=24.748-13.554 F n-2.046 A-0.353 T
\end{aligned}
$$


The Regression Model

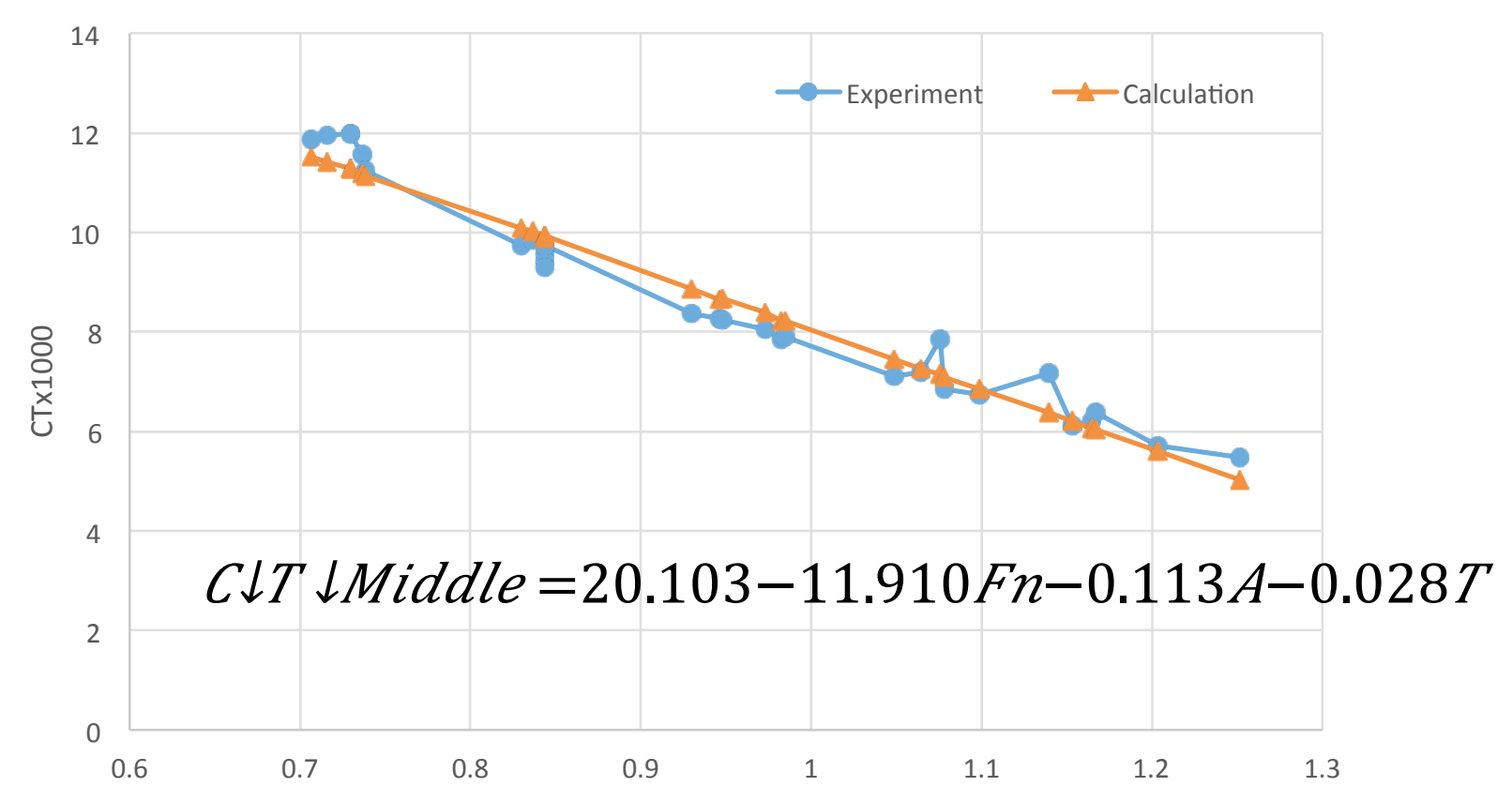

The total resistance coefficient $C_{T}$ vs Froude number measured for middle interceptor position compared with estimation. Triangle is model estimation, circle is experiment.

The average error compared to the model experiments is $6.9 \%$ in chine location of the interceptor, $5.2 \%$ in bottom location of the interceptor and $4.2 \%$ in the middle location of the interceptor 


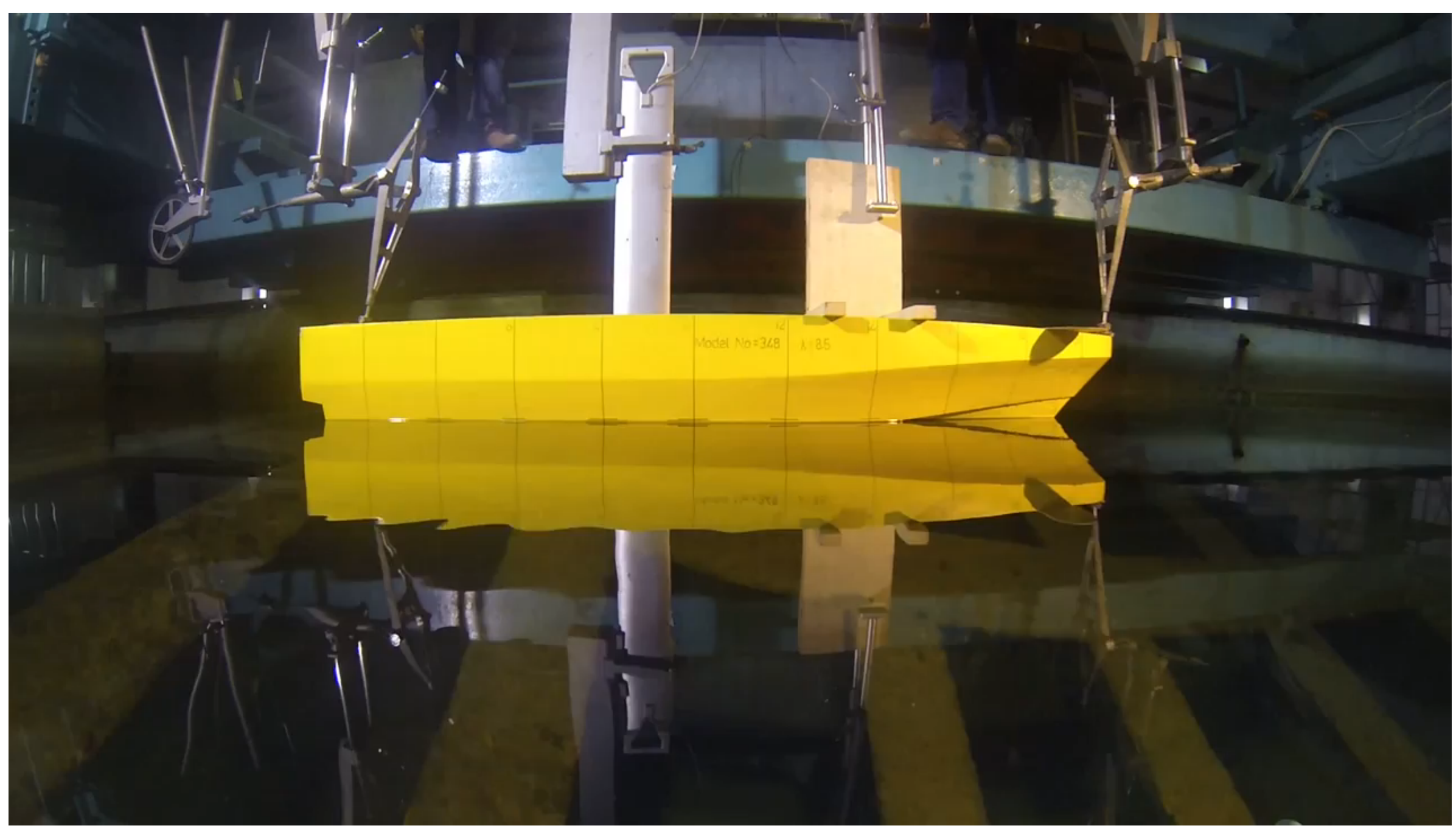




\section{Conclusion}

Resistance and running trim results showed characteristics common to planning craft.

The most important result is that interceptor blade depth have to be adjusted related to the operation speed.

$\checkmark$ Correspondingly, the study clearly states that, the interceptor systems decrease the unwanted trim angles in high speeds and increase the forward speed up to 4 to 5 knots in full scale, and gain approximately $14 \%$ fuel savings.

$\checkmark$ The system also decrease the wetted surface area and supplies a clear angle of sight for the boat operators.

$\checkmark$ For all three type of interceptor locations the interceptors increases the total resistance in slow speeds up to $\mathrm{Fn}=0.70$. After the boat starting its planning motion, the interceptor works in advance of reducing the total resistance coefficient $\mathrm{CT}$. Therefore, the authors advice to use dynamic interceptors in high speed boats. The interceptor blade depth have to be adjusted related to the operation speed.

$\checkmark$ According to the study, interceptor deployment is very important regarding to the advance speed of the hull. At high speeds, at high depth of interceptor deployment lets the hull making bow down motion and extreme spray so increasing the resistance. So, interceptor deployment should be arranged regarding to the speed and it has the be a dynamic blade deployment system with clever motions up to the speed. 


\section{Further Work}

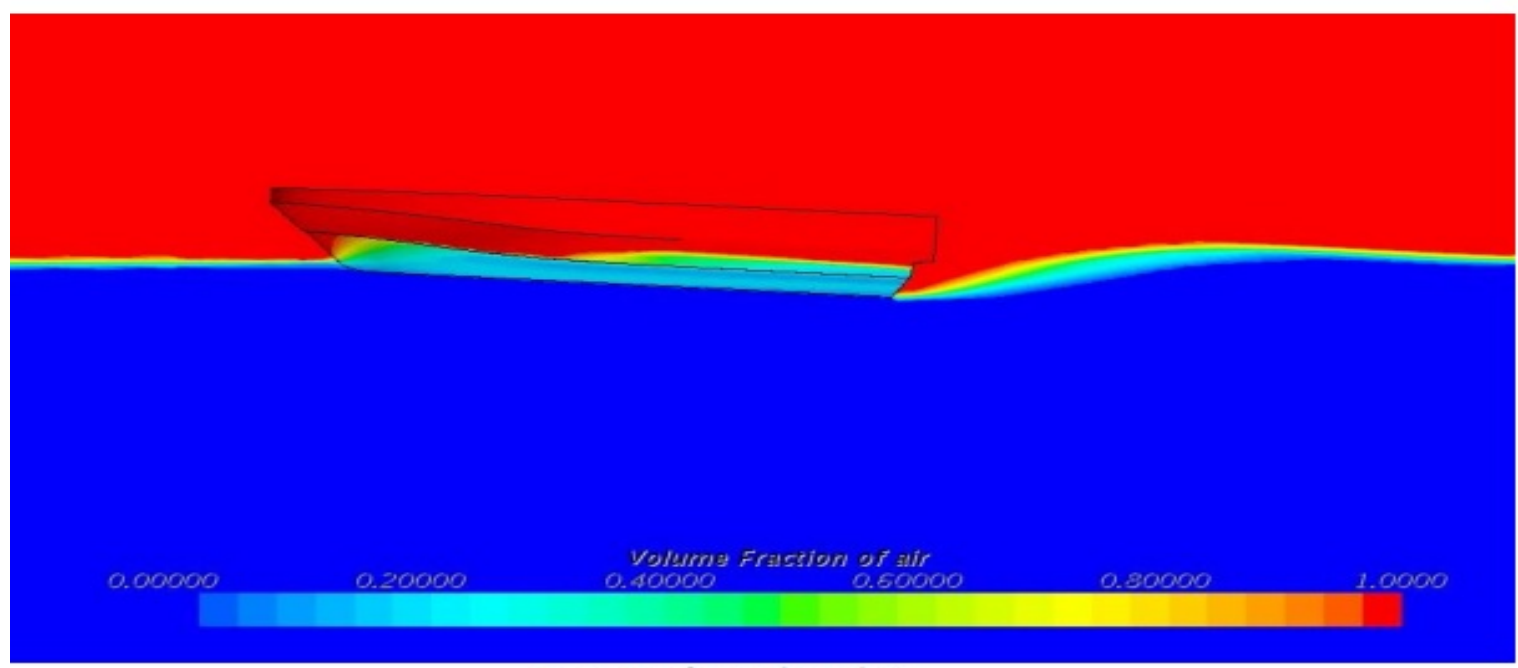

Free Surface Elevation 


\title{
Thanks for your patience
}

\author{
Any Questions?
}

\author{
Gültekin AVCI g.avci@itu.edu.tr \\ Barış BARLAS barlas@itu.edu.tr \\ Aykut I. ÖLÇER aio@wmu.se
}

